\title{
EFECTO DE LA RADIACIÓN ULTRAVIOLETA-B EN PLANTAS
}

\author{
EFFECT OF ULTRAVIOLET-B RADIATION IN PLANTS
}

\author{
Libertad Carrasco-Ríos ${ }^{1}$
}

\begin{abstract}
RESUMEN
La luz es uno de los factores más importantes que regulan el crecimiento y desarrollo de las plantas. Sin embargo, el aumento de la radiación ultravioleta-B debido a la acción antropogénica puede tener un impacto negativo en éstas, provocando una disminución de la fotosíntesis y de la producción de biomasa. Esta radiación puede además causar daño en distintas biomoléculas, entre la cuales la más importante es el DNA.

En este sentido, el presente trabajo analiza los estudios recientes sobre la respuesta del crecimiento de plantas expuestas a condiciones de alta radiación ultravioleta y los mecanismos de reparación molecular que en condiciones naturales generan las plantas como estrategia para protegerse de este tipo de radiación.

Palabras clave: Radiación UV, mecanismos de fotoprotección, implicancias ecológicas.
\end{abstract}

\begin{abstract}
The light is one of the most important factors that regulate growth and development of plants. However, the increase of the ultraviolet-B radiation due to the antropogenic action can have negative impacts on these processes, producing a decreased photosynthesis and biomass production. The ultraviolet radiation can damage different biomolecules in particular the DNA. This work analyse the last results reported on the responses of the growth of plants exposed to high levels of ultraviolet radiation and the repair mechanisms activated to protect plants against this type of radiation.
\end{abstract}

Key words: UV radiation, photoprotection, ecological aspects.

\section{INTRODUCCIÓN}

La radiación solar es uno de los principales factores ambientales que afectan la vida en nuestro planeta. Esta radiación controla el funcionamiento de los ecosistemas terrestres y acuáticos tanto a través del control de procesos fotobiológicos (fotosíntesis, fotoperíodo, fototropismos, etc.) como por medio de su acción sobre otros factores ambientales (temperatura, humedad, etc.) y ciclos naturales (ciclos diarios, anuales, hídricos, etc.) que finalmente inciden en la distribución de los organismos.

La radiación que llega a la Tierra abarca una amplia gama del espectro electromagnético y aproximadamente el $40 \%$ de ella es la que conocemos como luz o radiación visible. Esta comprende longitudes de onda que van de los 400 a los $700 \mathrm{~nm}$, rango que abarca los colores violeta, azul, verde, amarillo, naranja y rojo y que por ser usado por los vegetales en el proceso de la fotosíntesis, también se le denomina radiación fotosintéticamente activa o PAR (sigla derivada del inglés: photosynthetic active radiation).

Otro rango de esta radiación electromagnética es el que va de los $280 \mathrm{~nm}$ a los $1000 \mathrm{~nm}$, conocido como rango fotobiológico ya que comprende longitudes de ondas más allá de la radiación PAR y que son de importancia en otros procesos fotobiológicos bajo control de fotorreceptores específicos como por ejemplo los fitocromos.

Esta misma radiación solar, la cual ha hecho posible la vida sobre nuestro planeta, puede ser per-

1 Departamento de Química, Facultad de Ciencias, Universidad de Tarapacá. Arica-Chile. E-mail: lcarrasc@ uta.cl

Fecha de Recepción: 02 Julio 2009

Fecha de Aceptación: 15 Septiembre 2009 
judicial en altas intensidades o cuando la proporción de ondas cortas aumenta por sobre determinados límites. Altas intensidades de radiación y cambios en la composición espectral pueden afectar importantes procesos en los organismos, en particular en los vegetales que por no poder moverse sólo les queda adaptarse a tales cambios. Uno de los principales cambios que ha sucedido este último tiempo ha sido el aumento de la radiación UV-B (1). Esto, producto de la destrucción de la capa de ozono por compuestos contaminantes como los clorofluorocarbonos (CFC), óxidos de nitrógeno, cloro, bromo, etc. Estos compuestos tienden a formar compuestos estables con el ozono $\left(\mathrm{O}_{3}\right)$ con una vida media de 50 a 150 años (2). La radiación UV-B es aquella comprendida entre las longitudes de onda 280 y $320 \mathrm{~nm}$. Los otros componentes de la radiación UV son la radiación UV-C, comprendida entre los 200 y $280 \mathrm{~nm}$, y la UV-A entre los 330 y $400 \mathrm{~nm}$. Esta última radiación es poco absorbida por el $\mathrm{O}_{3}$, por lo que llega en mayor cantidad a la superficie de la Tierra y constituye una importante señal fotomorfogénica en las plantas y es la menos dañina. Por el contrario, la UV-C es la más energética y dañina para el ADN. Sin embargo, por ser la más absorbida por el oxígeno $\left(\mathrm{O}_{2}\right)$ y el $\mathrm{O}_{3}$ de la estratosfera prácticamente no llega a la superficie terrestre.

La destrucción de la capa de ozono ha sido más intensa en las latitudes altas, en particular en la Antártica, donde las concentraciones de ozono han disminuido entre un 40-50\% respecto a los valores obtenidos en 1980 y mínimos cambios en la zona del Ecuador en un $3-6 \%\left(35-60^{\circ} \mathrm{N}\right.$ y $\left.35-60^{\circ} \mathrm{S}\right)$, donde la radiación UV es intensa por naturaleza (3). Debido a esto, desde 1980 a la fecha, el flujo de radiación UV-B principalmente dentro del rango de los 290-315 nm ha aumentado en la tropósfera en promedio 6-14\% (4).

Si bien la radiación ultravioleta-B comprende una pequeña región del espectro electromagnético, su acción sobre plantas y animales es considerable. Esto principalmente debido a que importantes biomoléculas como proteínas y ácidos nucleicos, por presentar electrones $\pi$ la absorben fuertemente. Numerosos son los efectos atribuibles a esta radiación, la cual ha estado desde siempre presente en el ambiente ( $\underline{5})$. Así, las plantas desde temprano en su evolución han debido adaptarse a su presencia y desarrollar mecanismos capaces de disminuir sus efectos adversos. Por tal motivo, desde el descu- brimiento del denominado "agujero" de ozono en la Antártica, el interés por estudiar los principales efectos de la radiación ultravioleta-B sobre los vegetales ha aumentado considerablemente. Estos efectos se pueden clasificar en efectos anatomomorfológicos, metabólicos y moleculares. En este trabajo se analizan los principales estudios efectuados sobre los efectos de la radiación UV-B en las plantas con especial énfasis en aquellos efectos sobre los procesos metabólicos y moleculares.

\section{LOS EFECTOS DE LA RADIACIÓN UV-B SOBRE LA MORFOLOGÍA Y ANATOMÍA DE LAS PLANTAS}

Para que la radiación UV-B sea interceptada y produzca alteraciones en la fisiología de la planta debe penetrar en la hoja y ser absorbida por cromóforos o moléculas susceptibles al efecto dañino de esta radiación. Por lo tanto, los cambios morfológicos y anatómicos que son inducidos por la radiación UV-B pueden llegar a ser determinantes en las respuestas de las distintas especies vegetales sometidas a un aumento de este tipo de radiación. Así, frente a un aumento de la radiación UV-B muchos de los cambios observados, tanto en plantas monocotiledóneas como dicotiledóneas, son principalmente atribuidos a la orientación de las hojas que tiene cada uno de estos grupos de plantas, lo que finalmente influirá en la capacidad de interceptar este tipo de radiación. Las especies monocotiledóneas que presentan hojas delgadas con orientación vertical interceptan menos la radiación UV-B que las dicotiledóneas por presentar éstas hojas anchas y de orientación más bien horizontal, y por lo tanto son más susceptibles al daño ( $\underline{6})$. Por tal motivo, las plantas monocotiledóneas parecen ser generalmente más tolerantes a niveles elevados de radiación UV-B.

Por otra parte, las plantas aclimatadas a condiciones de alta radiación UV-B, como por ejemplo en alta montaña, se caracterizan principalmente por presentar tallos y ramas cortas, resultando plantas de morfología más bien compacta y de tamaño pequeño $(\underline{7}, \underline{8}, \underline{9})$. La disminución de la altura de las plantas expuestas a altas intensidades de radiación UV-B ha sido relacionada directamente con la inducción de internudos más cortos en distintas especies $(\underline{4}, \underline{7}, \underline{8}$, 9). Por tal motivo, se ha sugerido que el mecanismo por el cual la radiación UV-B reduce la longitud del tallo sería la oxidación de fitohormonas inductoras 
del tamaño de las células, como el ácido indolacético (IAA), el cual es susceptible a ser degradado por la radiación UV-B $(\underline{10})$.

Uno de los parámetros de crecimiento que es notablemente alterado por un aumento de la radiación UV-B es el área foliar. Su reducción ha sido ampliamente documentada en distintas especies cultivadas como: arveja $(\underline{11})$, pimentón $(\underline{12})$, soya $(\underline{13})$, etc. La disminución del área foliar, que se refleja en la presencia de hojas de menor tamaño (14), se produciría como consecuencia del efecto inhibitorio de la radiación UV-B sobre la expansión del epitelio de la cara adaxial que es la que normalmente recibe flujos de radiación UV-B mayores a la abaxial. Se ha demostrado que es la expansión de las células epiteliales la que regula el crecimiento foliar $(\underline{15})$ y la inhibición de la expansión observada en condiciones de alta radiación UV-B se produciría debido a un mayor entrecruzamiento de los enlaces formados entre carbohidratos y ácido ferúlico. Esto finalmente reduce la extensibilidad de la pared celular $(\underline{16})$, lo cual concuerda con lo encontrado por Liu y colaboradores, quienes observaron un aumento de la proporción de ácido ferúlico en el epitelio de hojas de cebada como respuesta a la radiación UV-B (17).

Por otra parte, diversos estudios sugieren que la primera causa de la reducción del área foliar está asociada a la inhibición de la división celular ( $\underline{18}$, 14), lo que ha sido observado en células epiteliales de hojas de trigo, en cotiledones de Cucumis sativus (19), hipocotilos de tomate (20), cultivo en suspensión de células de Petroselinum crispum (21) y en protoplastos de hojas de Arabidopsis thaliana (22). Este efecto inhibitorio de la radiación ultravioleta-B sobre la división celular se debería a la acción oxidativa de los fotones UV-B sobre las tubulinas que son proteínas que se ensamblan para formar el huso mitótico en la división celular (22) . Además, Logemann y colaboradores encontraron que la síntesis de histonas, proteínas que se unen al ADN formando la unidad estructural de la cromatina denominada nucleosoma, es reprimida transcripcionalmente por efecto UV-B (21). Resultado similar a lo obtenido en plantas de maíz donde también se observó una disminución de la histona $\mathrm{H} 4$ por efecto de la radiación UV-B, lo que estaría provocando alteraciones en la división celular por ausencia de la unidad estructural y móvil del ADN $(\underline{21}, \underline{23})$. Sin embargo, no está claro si la disminución de la división celular inducida por radiación UV-B es un efecto inhibitorio directo sobre las células potencialmente aptas para dividirse o el resultado de una respuesta coordinada de la planta a elevada radiación UV-B.

A lo largo de la evolución, la radiación UV-B ha inducido en las plantas diversos cambios anatómicos que han permitido modificar su intercepción y su penetración al interior de las células. Por ejemplo, el aumento de ceras y el cambio en la composición de éstas en la superficie foliar observado en especies expuestas a UV-B (24), favorece la reflexión de la luz UV-B desde la superficie foliar y contribuye a reducir la penetración de la radiación UV-B en las hojas (25). Por ejemplo, en coníferas esta penetración medida por medio de microsensores de fibra óptica resulta ser prácticamente nula, 3-12\% en plantas leñosas y hierbas y 18-41\% en plantas herbáceas dicotiledóneas ( $\underline{26})$. El aumento del grosor de las hojas es otro de los cambios anatómicos observado en plantas expuestas a radiación UV-B. Esto se debería al aumento del grosor de la pared celular como consecuencia de la inducción de síntesis de lignina y otros polifenoles $(\underline{7}, \underline{27})$.

Un porcentaje de la radiación UV-B que penetra a través de la hoja es absorbido por cromóforos asociados al aparato fotosintético $(\underline{4}, \underline{5})$, así, las respuestas fotomorfogénicas tienen un impacto directo sobre la mantención de la estructura y funcionamiento de éste. Por ejemplo, en diferentes cultivares de arroz se señala que niveles de radiación UV-B de 15-16 $\mathrm{kJ} \cdot \mathrm{m}^{-2}$ provocan destrucción de membranas en cloroplastos y desorganización de granas (르), en maíz una intensidad de $9 \mathrm{~kJ} \cdot \mathrm{m}^{-2}$ provoca colapso de la epidermis adaxial en la zona distal de las hojas (29) y una disminución en el número de cloroplastos en otras especies vegetales $(\underline{30})$, un mayor número de tricomas en la superficie de la cara adaxial $(\underline{30}, \underline{31})$ y una reducción en el número y diámetro de los tubos xilemáticos, así como disminución de la frecuencia estomática y del área foliar $(\underline{31}, \underline{32})$.

\section{ACCIÓN UV-B SOBRE PROCESOS FOTOQUÍ- MICOS Y METABÓLICOS}

Dentro de los procesos metabólicos afectados por la radiación UV-B se pueden resaltar aquellos relacionados con el metabolismo energético como lo son la fotosíntesis, aquellos relacionados con la síntesis de metabolitos secundarios, y finalmente aquellos relacionados con la detoxificación de especies reactivas de $\mathrm{O}_{2}$. 


\section{ACCIÓN UV SOBRE ANTENA COLECTORA Y FOTOSISTEMAS}

La inhibición del proceso de fotosíntesis en distintas especies de plantas por efecto de UV-B fue demostrada hace ya más de 20 años (19). Longitudes de onda ubicadas en la región ultravioleta del espectro resultan ser muy efectivas en la inactivación de la fotosíntesis $(\underline{33}, \underline{34})$. Los sitios del aparato fotosintético que se ven afectados por la luz ultravioleta-B son: el complejo colector de luz II ((LHCII, del inglés light center harvesting), el centro de reacción del fotosistema II (PSII, del inglés photosynthetic system) y el aceptor del fotosistema I, PSI $(\underline{35}, \underline{36})$. Sin embargo, la mayor parte de los estudios han demostrado que el fotosistema II es más sensible a la radiación UV-B que el fotosistema I ( $\underline{37})$.

\section{EFECTO UV-B SOBRE LAS PROTEÍNAS $Y$ LOS PIGMENTOS DE LAS ANTENAS COLECTORAS}

La alta eficiencia de la transferencia de energía que se produce en el PSII depende de la estructura específica de las proteínas que lo conforman y encargadas de proporcionar la orientación y configuración óptima que garantice la conducción de la energía entre los distintos complejos de las membranas tilacoidales ( $\underline{38})$. Por lo tanto, cualquier alteración que se produzca en estas proteínas por efecto UV-B afectará también a las propiedades de los pigmentos asociados y de otros cofactores que en conjunto hacen posible el proceso fotosintético (38).

En general, la radiación UV-B induce la pérdida de polipéptidos localizados en el PSII tales D1, D2, CP47, CP43 y de enzimas del ciclo de Calvin (39). Las proteínas son moléculas orgánicas que contienen en su estructura aminoácidos aromáticos como la tirosina, fenilalanina y triptófano, los que presentan electrones del tipo $\pi(\underline{40})$. Los fotones del tipo ultravioleta, que son más energéticos que los del tipo visible, son capaces de promover transiciones electrónicas $\pi$ - $\pi *$ y de esta manera inducir transformaciones químicas que afectan directamente el establecimiento de enlaces químicos, lo que altera la estructura de las moléculas que los poseen (41). Así, diversos estudios indican que la absorción de radiación UV-B por parte de aminoácidos cíclicos induce la oxidación no específica de éstos alterando su conformación y finalmente la funcionalidad de las proteínas. Esto puede llegar a afectar significativamente la vida de las plantas dado que los mecanismos de reparación basados en la capacidad de síntesis y en la tasa de reposición de las proteínas pueden ser sobrepasados por el efecto de la radiación UV-B $(\underline{19}, \underline{40})$.

En este sentido, el principal efecto de la radiación UV-B sobre el PSII se produce específicamente en la proteína D1 (2), donde la energía de los fotones UV-B rompe esta proteína en el segundo segmento transmembranal, dando origen a fragmentos C-terminal de $20 \mathrm{kDa}$ y $\mathrm{N}$-terminal de $10 \mathrm{kDa}(\underline{36}$, 43). El aumento de la degradación de la proteína D1 bajo radiación UV-B puede ser explicado como consecuencia de dos mecanismos independientes. El primero producido por el daño directo al cluster de manganeso implicado en la oxidación del agua, lo que provoca el rompimiento de la proteína D1 $(\underline{35}, \underline{42}, \underline{43}, \underline{44})$. El segundo mecanismo que explica la degradación de la proteína D1 por efecto de la radiación UV-B implica la inducción de defosforilación de proteínas del PSII, que ocurre por la interrupción del transporte lineal de electrones y que afecta la producción de ATPY NADPH, lo cual favorece el recambio de proteínas D1, de acuerdo al modelo propuesto por Aro y colaboradores en $1997(\underline{39}, \underline{45})$.

La síntesis e inserción de nuevas proteínas D1, así como la transcripción, traducción y elongación del péptido naciente dependen también de la luz visible (46). Independientemente del mecanismo del daño, la recuperación de la fotoinhibición del PSII depende de la síntesis in novo de la proteína D1 y de su reensamblaje en el centro de reacción del PSII $(\underline{47}, \underline{48})$. Este es un proceso que ocurre continuamente y es independiente del daño inducido por radiación ultravioleta-B y sólo la proteína D1 es sintetizada de novo (트). La defosforilación reversible de polipéptidos tales como CP43 y D2 también estaría implicada en el desmantelamiento de los centros dañados (45), y tanto CP43 como D2 serían recicladas para reconstituir la funcionalidad de los centros de reacción del PSII (흐) aunque algunos estudios indican que las distintas proteínas CP tendrían una baja capacidad de restauración una vez provocado el daño en el PSII por radiación UV-B (노).

Además, la pérdida de la capacidad de restauración de la proteína D1 que ocurre tanto a altas intensidades de luz visible y de radiación UV-B (흐), se ha relacionado directamente con la disminución 
de clorofilas $a$ y $b$ (49). La disminución del contenido de pigmentos fotosintéticos localizados en los LHC por efecto del aumento de luz ultravioleta-B, ha sido observada en distintas especies cultivadas y la tolerancia que puedan presentar algunas especies frente a un aumento de la radiación ultravioleta-B se relaciona con la capacidad de las plantas de mantener la clorofila en sus hojas $(\underline{4}, \underline{50})$. Es así como la reducción del contenido de clorofilas por efecto de luz ultravioleta-B puede llegar al 33\% en especies monocotiledóneas tales como maíz y sorgo (ㅁ) y en dicotiledóneas la disminución puede ser de un $10 \%$ en el caso de la soya hasta un $78 \%$ en poroto según Mirecki y Teramura (1) .

La pérdida de pigmentos que se observa bajo condiciones de radiación UV-B se debería principalmente a que la degradación de la proteína D1 provoca la desorganización de los centros de reacción y, en consecuencia, la liberación de los complejos CP47 y CP43 (푸). La presencia de cloroplastos modificados estructuralmente en plantas expuestas a UV-B, con un menor número de granas y menor cantidad de tilacoides por grana avalan estas observaciones $(\underline{4}, \underline{26}, \underline{52})$ y en este sentido, la disminución del contenido de clorofila $a$ y $b$ en plantas tratadas con luz UV-B sería resultado de la parcial desorganización de las granas, lo que confirmaría el daño que induce la radiación UV-B en el PSII (39). Además, la pérdida de proteínas del LCHII directamente implicada en el proceso de captación de luz como CP43 y CP47 (포, $\underline{44}, \underline{53}$, 54) provocaría la liberación de clorofilas, las que en estado libre son destruidas por fotooxidación $(\underline{35}, \underline{55})$.

La destrucción fotooxidativa de las clorofilas libres puede producirse también debido a la fotoinhibición del PSII por el lado dador de electrones. Aunque este tipo de fotoinhibición ha sido informado por distintos investigadores como uno de los eventos que se desencadenan bajo condiciones de radiación UV-B, para otros este daño es de carácter secundario (35). La fotoinhibición del PSII observada en condiciones de luz visible y UV-B promueve la formación del par radical $\mathrm{P} 680^{+} / \mathrm{Pheo}^{-}$una vez que ocurre la primera separación de carga entre el dímero de clorofila (P680) y una molécula de feofitina "Pheo" en el centro de reacción del PSII ( $\underline{35})$. Bajo exceso de radiación esta situación tiende a la recombinación de carga, lo que además da lugar a la formación del triplete de P680 ('3P680), el cual al interactuar con el $\mathrm{O}_{2}$ genera oxígeno singlete $\left({ }^{1} \mathrm{O}_{2}\right)$ que es un potente agente oxidante $(\underline{35}, \underline{56})$. El alto potencial oxidante del P680 actuaría oxidando membranas tilacoidales, proteínas cercanas como D1, D2, CP43, CP47 (노, 57) y clorofilas que al estar libres son propensas a la fotooxidación ( $\underline{35})$.

Independiente del tipo de fotoinhibición al que es sometido el PSII en condiciones de alta radiación UV-B, la interrupción del transporte lineal de electrones termina por afectar finalmente la producción de ATP y NADPH, elementos esenciales en la fijación de $\mathrm{CO}_{2}$ en el ciclo de Calvin $(\underline{35}, \underline{44}, \underline{58})$.

Por otra parte, la radiación UV-B afecta también la expresión de distintos genes por daño directo en moléculas de $\operatorname{ADN}(\underline{59}, \underline{60})$. Por ejemplo, Broshe y colaboradores informan de la influencia de la radiación UV-B en la expresión de genes relacionados con proteínas y componentes del PSII (59). De la misma manera, Casati y Walbot, en genotipos de maíz con variados contenidos de flavonoides, encontraron que la expresión de genes asociados a la fotosíntesis disminuía en condiciones de radiación ultravioleta-B y que aumentaba la expresión de genes que codifican la síntesis de ubiquitinas, proteínas que marcan a otras proteínas para la posterior degradación ( $\underline{60})$.

\section{EFECTO UV-B SOBRE ENZIMAS DEL CICLO DE CALVIN}

Distintas investigaciones han informado que la radiación UV-B induce la pérdida de actividades enzimáticas del ciclo de Calvin, con especial énfasis en la disminución directa de la enzima ribulosa 1,5 difosfato carboxilasa (Rubisco) que cataliza la incorporación de $\mathrm{CO}_{2}$ en el ciclo de Calvin $(\underline{6}, \underline{61})$. Allen y colaboradores, en 1997, demostraron que la radiación UV-B disminuye la tasa de asimilación neta de $\mathrm{CO}_{2}$ en hojas maduras de Brassica napus y que de acuerdo al modelo de von Caemmerer y Farquhar (62), la disminución de la tasa neta de asimilación de $\mathrm{CO}_{2}$ medida en condiciones de saturación luminosa (Asat) es acompañada por la disminución de la velocidad máxima de carboxilación de la Rubisco (Vcmax), resultados que fueron confirmados por medio de ensayos in vitro de actividad Rubisco ( $\underline{63})$.

La disminución de la actividad y cantidad de Rubisco inducida por luz ultravioleta-B ha sido informada por distintos investigadores $(\underline{6}, \underline{64}, \underline{65})$. La disminución de la actividad de la enzima Rubisco en condiciones de radiación UV-B es atribuida en 
la mayoría de los casos a una baja disponibilidad de sustrato ribulosa-1,5-bisfosfato, que ocurre a causa de la disminución de la velocidad máxima del transporte de electrones, proceso que limita la disponibilidad de NADPH y ATP requeridos en la síntesis de ribulosa-1,5-bisfosfato $(\underline{17}, \underline{65})$.

Otra acción atribuida a la radiación ultravioleta- $\mathrm{B}$ es la inducción de senescencia a través de la activación de proteasas específicas como ubiquitinas que degradarían las enzimas del ciclo de Calvin (ㄴ1, $\underline{59}, \underline{66})$.

\section{EFECTO DE LA RADIACIÓN UV-B SOBRE EL METABOLISMO SECUNDARIO}

Uno de los mecanismos de adaptación a radiación UV-B más documentado es el aumento de la producción de metabolitos secundarios tales como fenoles y flavonoides, los que se acumulan en las células de la epidermis de diversas especies vegetales, y por ser compuestos que absorben radiación entre los 280-360 nm, reducen el efecto deletéreo de la luz UV-B sobre los distintos componentes celulares $(\underline{5}, \underline{67}, \underline{68}, \underline{69})$.

\section{SÍNTESIS DE TERPENOIDES}

Los terpenoides son compuestos que presentan gran diversidad estructural y muchos de ellos actúan como toxinas y repelentes de herbívoros. Muy poco se conoce del efecto de la radiación UV-B sobre la síntesis de terpenoides y de los estudios existentes se sabe que la radiación UV-B induce el aumento del contenido de terpenos en hojas de Ocimum basilicum (70) y Grindelia chiloensis (71). Dentro de este grupo de metabolitos secundarios se encuentran también los carotenoides, que son pigmentos accesorios bien caracterizados en su rol fotoprotector y que aparentemente no son afectados por un aumento de radiación UV-B en especies tales como Cucumis sativus, Helianthus annus (72) у Hordeum vulgare (73). Sin embargo, en Glycine max y Oryza sativa se ha observado una marcada reducción en condiciones de elevada radiación UV-B (74), mientras que en Phaseolus vulgaris, el aumento o disminución del contenido de carotenoides ha dependido de los niveles de radiación PAR y UV-B a las que han sido expuestas las plantas (프).

\section{SÍNTESIS DE ALCALOIDES}

Los alcaloides tales como la atropina, morfina, codeína, heroína, nicotina, cafeína, cocaína, etc., son compuestos ampliamente reconocidos por su efecto farmacológico y en las plantas actúan como agentes defensivos y como feromonas. Si bien han sido poco estudiados, estos compuestos absorben fuertemente radiaciones comprendidas en el rango UV y tendrían un rol protector frente a este tipo de radiación (76). En Cannabis sativa, el aumento de la radiación UV-B induce la síntesis canabinoides (77), así como en Trifolium repens donde la radiación UV-B aumenta significativamente la producción de cianógenos (묘).

\section{SÍNTESIS DE FENILPROPANOIDES}

Los fenilpropanoides son metabolitos secundarios del tipo fenólico y al igual que los anteriores han sido implicados en la respuesta de defensa contra insectos herbívoros. Dentro de este grupo se encuentran las ligninas, suberinas, estirilpironas, estilbenos, cumarinas, furanocumarinas, taninos y flavonoides. La implicancia de los flavonoides en la respuesta a radiación UV-B ha sido informada por distintos investigadores y en especies de plantas tales como Arabidopsis thaliana, Licopersicum esculentum, Triticum aestivum, Oryza sativa, Phaseolus vulgaris, Trifolium repens, Zea mays, por citar algunas $(\underline{20}, \underline{28}, \underline{60}, \underline{67}, \underline{79}, \underline{80}, \underline{81})$. La acumulación de flavonoides, frecuentemente observada en respuesta a radiación ultravioleta-B, también ha sido relacionada con su potencial acción antioxidante frente a radicales libres $(\underline{81})$. No obstante, la función antioxidante de los flavonoides es compleja y depende de una variedad de factores, los que incluyen su compartimentalización, potencial redox, presencia de dobles enlaces, glicosilación y niveles de hidroxilación.

Los compuestos absorbedores de UV tales como fenoles y flavonoides son inducidos por radiación UV-B, acumulándose preferentemente en las células de la epidermis y son capaces de absorber la radiación UV-B no interfiriendo en la absorción de la radiación fotosintéticamente activa (PAR) $(\underline{5}, \underline{67}, \underline{68})$.

El rol protector de estos compuestos en plantas sometidas a condiciones de radiación ultravioleta-B ha sido sustentado principalmente por experimentos realizados en mutantes de Arabidopsis. Sin lugar a dudas, el aislamiento y la caracterización de mutantes a radiación ultravioleta ha sido una poderosa herramienta para el entendimiento de los mecanismos que protegen a las plantas contra el daño inducido 
por radiación ultravioleta-B. Bieza y Lois, en 2001, señalan que el mutante de Arabidopsis thaliana $u v t 1$ exhibe una marcada tolerancia a altos niveles de radiación UV-B y observan que la inducción de la síntesis de compuestos absorbedores bajo estas condiciones aumenta la capacidad de las hojas de bloquear este tipo de radiación (2ㅡ). De esta manera, estos autores atribuyen a los flavonoides la elevada resistencia de las mutantes $u v t l$ a condiciones letales de radiación ultravioleta. Lo mismo fue observado en la planta Arabidopsis tt5, que es una mutante virtualmente incapaz de sintetizar flavonoides y que se afecta significativamente al ser expuesta a radiación UV-B $(\underline{82}, \underline{83})$.

La generación de fenotipos hipersensibles a radiación ultravioleta está íntimamente relacionada con la eficiencia que presenten las enzimas que participan en la biosíntesis de los fenilpropanoides y entre ellos los flavonoides tales como la fenilamonio liasa (PAL), chalcona sintetasa (CHS) y chalcona isomerasa (CHI) (67). En trabajos realizados en hojas de petunia se demuestra que la luz ultravioleta-B induce la síntesis de flavonoles debido a la sobrerregulación de distintos genes que participan en la síntesis de los fenilpropanoides (부). Al comparar la producción de flavonoides entre la variedad salvaje de petunia y el mutante $F 3$ ' $H$ deficiente en la enzima flavonoide 3'-hidroxilasa se observó bajo alta radiación UV-B un aumento de flavonoides en la línea tipo salvaje (con predominancia de dihidroxiquercetina) respecto del mutante $F 3^{\prime} H$ en donde el contenido de flavonoides disminuyó significativamente (con predominancia del kaempferol). La enzima flavonoide 3'-hidroxilasa es la encargada de convertir al flavonol monohidroxilado denominado dihidrokaempferol a un tipo de flavonol dihidroxilado conocido como dihidroquercetina. Con este estudio se establece que los flavonoides inducidos por radiación ultravioleta-B presentan altos niveles de hidroxilación y que la enzima flavonoide 3'-hidroxilasa sobrerregula todos los genes que participan en la biosíntesis de los flavonoides, como lo documentan otras investigaciones $(\underline{68}, \underline{84})$. Asimismo, trabajos realizados en hojas de Arabidopsis L. tipo salvaje muestran que al exponer estas plantas a bajos niveles de radiación ultravioleta-B el contenido de kaempferol resulta superior al de quercetina. Sin embargo, bajo condiciones de alta radiación UV-B el contenido de flavonoides se duplica con un mayor aumento de quercetina respecto de kaempferol. Estos resultados reafirman que los flavonoides protegen a las plantas de Arabidopsis del daño por radiación ultravioleta-B e indican que la enzima flavonoide 3'-hidroxilasa $\left(F 3^{\prime} H\right)$ juega un rol crucial en esta respuesta a la luz UV-B. Los autores también concluyen que la quercetina es un fotoprotector más eficiente que el kaempferol y de mayor capacidad antioxidante (무), lo cual también ha sido determinado en Vicia faba en donde en condiciones de alta radiación UV-B se indujo un aumento en la producción de quercetina particularmente localizada en las células de la epidermis, mientras que la síntesis de kaempferol resultó presentar un carácter constitutivo $(\underline{85}, \underline{86})$.

Todas estas investigaciones indican que los flavonoides hidroxilados junto con los dihidroxilados confieren una protección adicional contra la UV-B, lo que sería mediado por su relativa capacidad antioxidante, que se dirigiría fundamentalmente hacia los radicales hidroxilos y superóxidos, especies altamente reactivas implicadas en el inicio de la cadena de peroxidación lipídica $(\underline{5}, \underline{81})$. De esta manera, los trabajos citados establecerían que la hidroxilación no afecta las propiedades absorbedoras de radiación UV de estos compuestos, pero sí su capacidad antioxidante, lo que sugiere que los flavonoides juegan un rol no caracterizado aún en la respuesta a estrés por radiación UV-B.

Por otra parte, las antocianinas también tendrían un rol protector frente a la radiación UV-B, lo que ha sido informado por distintos investigadores, quienes demuestran que extractos purificados de antocianina presentan propiedades fuertemente antioxidantes al atrapar especies reactivas de oxígeno en células vivas in vitro (7). De la misma manera, Stapleton \& Walbot demostraron que las plantas de maíz (Zea mays) que contienen flavonoides, principalmente antocianinas, eran protegidas del daño generado en el DNA por radiación ultravioleta y que las plantas deficientes en este tipo de compuestos inducían la formación de dímeros de pirimidina ciclobutano (CPDs) y dímeros de pirimidina pirimidona $(6,4$ PPs) en el DNA (ㅁ8).

\section{EFECTO UV-B SOBRE LA GENERACIÓN DE ESPECIES REACTIVAS DE OXÍGENO (ROS)}

Distintos estudios han relacionado el aumento de radiación UV-B con la generación de especies ROS, dando cuenta además de la activación de mecanismos de defensa similares a los desarrollados en ataque de patógenos, lo que sugiere que la radiación 
UV-B activaría procesos de lipoperoxidación en la membrana plasmática $(\underline{56}, \underline{89}, \underline{90}, \underline{91})$. Estudios moleculares realizados en Nicotiana longiflora dan una clara convergencia entre las respuestas generadas en ambos estreses (radiación UV-B y ataque de patógeno); los cambios transcripcionales observados mediante microarreglos en ambas situaciones son similares en varias categorías funcionales de genes en magnitud y dirección (91).

Es así como A-H-Mackerness y colaboradores (2001) investigaron la naturaleza y el origen de los ROS implicados en la cascada de señales que son inducidas tempranamente por efecto de radiación UV-B (90). Empleando inhibidores enzimáticos y compuestos atrapadores de radicales libres, estos investigadores observaron que los transcriptos de genes $P R I$ aumentaban en respuesta a la exposición a UV-B y que tal aumento resultó ser mediado por $\mathrm{H}_{2} \mathrm{O}_{2}$ derivado del ión superóxido $\left(\mathrm{O}_{2}^{-}\right)$, mientras que los transcriptos de genes PDF1.2 fueron sobrerregulados pero mediante la vía que involucraba directamente $\mathrm{O}_{2}^{-}$. Lo interesante en este trabajo es que los genes que codifican la expresión de la enzima CHS también se sobrerregularon por radiación UV-B, pero sin participación de los ROS ya que los compuestos atrapadores de óxido nítrico (NO) e inhibidores de la enzima óxido nítrico sintasa (NOS) modularon la expresión génica de la enzima CHS (무).

En plantas de Arabidopsis sometidas a radiación UV-B fue observado también que la expresión de genes relacionados con la patogénesis $P R I$ y $P D F 1.2$ se bloqueaba al pretratar las plantas con ácido ascórbico, lo que indica que durante la respuesta al efecto de la radiación UV-B se generan especies reactivas de oxígeno, los que finalmente inducen la expresión de estos genes (92). Similares observaciones obtuvieron Rao y Ormrod, quienes aumentaron la tolerancia a UV-B en mutantes de Arabidopsis incapaces de sintetizar flavonoides $(t t 5)$, por medio de ácido ascórbico y glutatión, compuestos atrapadores de especies reactivas de oxígeno ( $\underline{83})$.

Estos resultados dan clara evidencia de que la exposición a radiación ultravioleta-B induce un estrés oxidativo en las plantas, lo que provoca la generación de los ROS, y que la molécula de NO podría ser otra señal molecular que actuaría modulando la respuesta a radiación UV-B por medio de la activación de genes específicos como el de la enzima chalcona sintetasa (무).
Por otra parte, en plantas de maíz expuestas a radiación UV-B (무), el aumento de la expresión de genes de proteínas antioxidantes como la ascorbato peroxidasa es consistente con resultados en otras especies monocotiledóneas en respuesta a radiación ultravioleta-B (3). Por lo tanto, la radiación UV-B provoca una explosión oxidativa a nivel celular e induce cambios significativos en un grupo importante de proteínas como lo son las enzimas antioxidantes superóxido dismutasa, catalasa, peroxidasa, glutatión reductasa y ascorbato peroxidasa, además de las moléculas antioxidantes como el glutatión, ascorbato, $\alpha$-tocoferol y carotenoides, lo que demuestra la participación de especies reactivas de oxígeno (ROS) en la respuesta a UV-B (94). Además, las diferentes especies reactivas de oxígeno generadas por efecto de la radiación UV-B actuarían no tan solo como radicales destructivos a nivel celular sino también como señales moleculares esenciales para gatillar modificaciones en la expresión de genes y así contrarrestar el efecto de la radiación UV-B sobre las plantas. Las "RNS" (del inglés de "reactive nitrogen species") también estarían implicadas en la activación de genes involucrados en la respuesta a UV-B (무).

\section{ACCIÓN UV-B SOBRE ELADN}

El ADN es particularmente sensible a radiación UV-B, debido a que los fotones del tipo ultravioleta promueven transiciones $\pi-\pi^{*}$ en las bases nitrogenadas que constituyen los nucleótidos alterando directamente el establecimiento normal de enlaces químicos (도). La fototransformación producida en el ADN afecta principalmente a bases de timina adyacentes, las que por efecto de la radiación UV-B forman estructuras cíclicas denominadas dímeros de pirimidina ciclobutano (CPDs) (96) (Figura 1).

Bajo condiciones de radiación UV-B no sólo se observan lesiones en el ADN del tipo CPDs, también esta radiación induce la formación de otros fotoproductos denominados dímeros de pirimidina pirimidona (6-4 PPs) entre bases adyacentes de timina y citosina (Figura 1), y en el caso del RNA dímeros de uracilo (97).

Del total de las lesiones provocadas por la radiación UV-B sobre el ADN, el 75\% corresponde a los CPDs y el resto a fotoproductos de pirimidina (6-4) pirimidona (요). Ambos tipos de dímeros alteran los procesos de transcripción de genes y de duplicación del ADN, debido a que tanto la 

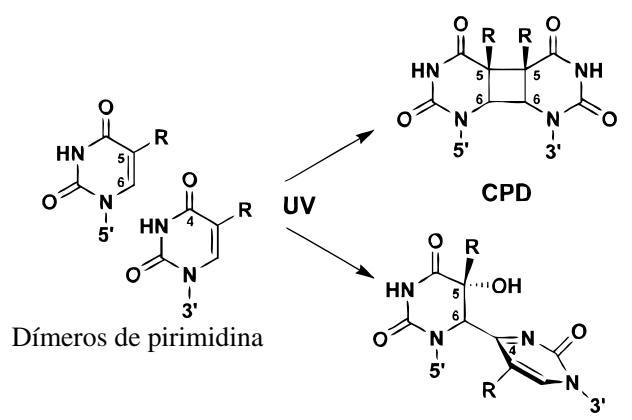

(6-4) fotoproductos

Figura 1. Estructuras de lesiones en el ADN inducidas por radiación $\mathrm{UV}-\mathrm{B}$.

ADN polimerasa como la ARN polimerasa no son capaces de leer la hebra de ADN a través de estos fotoproductos $(\underline{99}, \underline{100})$. Por tal motivo, la eliminación de los CPDs y 6-4 PPs resulta esencial para la supervivencia de las distintas especies afectadas por este tipo de daño (9) $)$.

Para contrarrestar el efecto dañino de la radiación UV-B sobre el ADN, los organismos han desarrollado dos tipos de mecanismos de reparación: la fotorreactivación y la reparación por excisión de bases y/o nucleótidos $(\underline{100}, \underline{101})$. En plantas, la vía de reparación de mayor prevalencia es la fotorreactivación $(\underline{102}, \underline{103})$.

El mecanismo de reparación denominado fotorreactivación es un proceso enzimático, donde la enzima DNA-fotoliasa ejerce la acción reparadora sobre el DNA, la que consiste en monomerizar los dímeros de pirimidina. Este proceso es dependiente de luz y la enzima DNA-fotoliasa, proteína monomérica de 50-60 kDa, presenta dos cromóforos que absorben en el rango de luz UV-A (350-400 nm) y luz azul (103).

La fotoliasa específica para CPD de microorganismos, denominada fotoliasa clase I, fue la primera de la familia de enzimas fotoliasas en ser caracterizada por Sancar en 1994 (9) $)$. En plantas, las CPD fotoliasas designadas fotoliasas clase II han sido identificadas en distintas especies tales

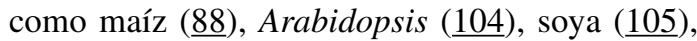

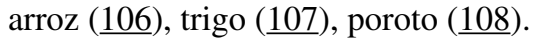

La secuencia de esta enzima en Arabidopsis thaliana muestra una considerable analogía con la DNA-fotoliasa originalmente descrita en procariontes, lo que indicaría que la función reparadora de esta enzima se habría originado muy temprano en la evolución y que al menos desde el paso de los procariotas a sistemas multicelulares, hace 1000 millones de años, la función de esta enzima no se habría alterado mayormente a pesar de la enorme cantidad de años y del drástico descenso de los niveles de radiación UV-B acaecido hace unos 700-800 millones de años (109).

El mecanismo que emplean estas enzimas para reparar las zonas dañadas de ADN por efecto de radiación UV-B ha sido principalmente estudiado por medio de espectroscopía de resonancia Raman $(\underline{96}, \underline{110})$ e indica que las fotoliasas reconocen la "lesión sustrato" enlazándose sobre la zona dañada del ADN y de esta manera gatillan el cambio conformacional de la molécula de DNA en $36^{\circ}$, lo que posiblemente permite la eliminación de los fotoproductos $(\underline{111}, \underline{101})$. Todas las fotoliasas caracterizadas contienen a la coenzima FAD (Flavin adenina dinucleótido) reducida y un segundo cromóforo que dependiendo de la especie podrá ser el 5,10-methenyltetrahydrofolate (MTHF) (fotoliasa Tipo I) o el 8-hydroxy-5-deasa-riboflavin (8-HDF) (fotoliasa Tipo II) (112). Los mecanismos de reacción propuestos para ambas clases de fotoliasas son similares, donde los cromóforos MTHF o 8-HDF funcionan como fotoantenas absorbiendo luz azul, la que es posteriormente transferida para reducir a la coenzima FAD. La coenzima reducida $\left(\mathrm{FADH}^{-}\right)$ cede el electrón al CPD, provocándose el arreglo electrónico dentro de la estructura cíclica de los fotoproductos. Lo anterior da lugar al rompimiento de los anillos de ciclobutano, con lo que finalmente se restaura la integridad de las bases en la molécula de $\operatorname{ADN}(\underline{99}, \underline{112}, \underline{113}, \underline{101})$.

En experimentos realizados con mutantes de Arabidopsis thaliana (uvr2-1) deficientes en fotoreparar los dímeros de ciclobutilpirimidina (CPDs), se ha observado que a bajos niveles de luz UV-B se inhibe el crecimiento de la planta y que la mutante $u v r 2$ es incapaz de remover CPDs in vivo (114). La clonación y secuenciación de los genes de la enzima fotoliasa de la mutante de Arabidopsis thaliana $u v r 2-1$ da cuenta de alteraciones en el ADN, específicamente en la parte superior del cromosoma 1 que afecta directamente al gen estructural de la enzima fotoliasa tipo II, lo que conduce a la síntesis de una proteína defectuosa $(\underline{115})$. Estos resultados y específicamente la mutante $u v r 2-1$ proveen la evidencia suficiente para afirmar que la enzima CPD fotoliasa es requerida para la supervivencia de la planta en presencia de radiación UV-B y que 
en general los mutantes sensibles a radiación UV-B no son capaces de reparar su ADN dañado por luz UV-B $(\underline{104}, \underline{114})$.

Por otra parte, en Arabidopsis thaliana se han identificado dos tipos de fotoliasas que desempeñan funciones específicas, una para la fotorreparación de dímeros de ciclobutano pirimidina y otra para la fotorreparación de los 6-4 PPs $(\underline{99}, \underline{115})$, las que desempeñarían diferentes roles de protección frente a radiación UV-B. En el caso de la CPD fotoliasa, la luz blanca y UV-B inducen la expresión de esta enzima en tejidos de Arabidopsis, en contraste con la enzima 6-4 PPs fotoliasa, la que se expresa constitutivamente y no regulada por luz blanca ni UV-B (9). Además, ambas fotoliasas serían capaces de remover los fotoproductos del ADN en plantas expuestas a condiciones de alta radiación UV-B y elevada temperatura, pero la velocidad de remoción de los CPDs sería menor (9ㅗ).

En vegetales, además de la fotorreparación del ADN a través de la enzima ADN-fotoliasa, existe el mecanismo de reparación oscura denominado así porque ocurre en ausencia de luz $(\underline{102}, \underline{101})$. Este mecanismo, universalmente conocido como mecanismo de reparación por excisión, ya sea de nucleótidos (NER) o de bases nitrogenadas (BER), involucra la acción concertada de distintos productos génicos, algunos de los cuales han sido identificados en plantas $(\underline{102}, \underline{116}, \underline{101})$. Una amplia gama de lesiones que distorsionan la forma helicoidal del ADN como los CPDs y 6-4 PPs son reparadas por $\operatorname{NER}(\underline{102}, \underline{101})$.

El mecanismo de reparación por excisión de nucleótidos implica el reconocimiento de la zona de ADN dañada, incisión en la hebra de ADN, excisión de los oligonucleótidos que contienen la lesión, síntesis y ligación del DNA. Kimura y colaboradores evaluaron la actividad reparadora del ADN en diferentes tejidos de plantas de arroz, observando que la reparación a través de fotoliasas $\mathrm{y}$, por excisión se correlacionaba de manera directa con la proliferación celular y que la expresión de distintos genes relacionados con la reparación oscura era elevada en tejidos meristématicos a diferencia de lo observado en células no proliferativas donde sólo se observa actividad CPD fotoliasa $(\underline{103}, \underline{117})$.

Si bien se ha informado que el mecanismo de reparación de DNA por excisión es muy activo en células vegetales en proliferación $(\underline{103}, \underline{108})$, la fotorreactivación es sin lugar a dudas la mayor vía de reparación de ADN en células no proliferativas que están continuamente bajo el efecto de la luz y

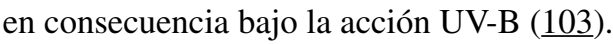

IMPLICANCIAS ECOLÓGICAS DE LAS RESPUESTAS DE LAS PLANTAS A LA RADIACIÓN $U V-B$

La productividad de los cultivos en el campo no solo depende de la sensibilidad que presenten las distintas especies al efecto de la radiación UV-B, también depende de la interacción con otros factores bióticos y ambientales (118). En este sentido, en el contexto del cambio climático experimentado en el último tiempo, se ha observado además del aumento de la radiación UV-B, un aumento del $\mathrm{CO}_{2}$ y de la temperatura, así como cambios significativos en la frecuencia y calidad de las precipitaciones (119). Incluso, el consenso científico predice un aumento global de la temperatura entre 1.5 y $4.5^{\circ} \mathrm{C}$ en los próximos 100 años, sumado al ya existente aumento de $0.6^{\circ} \mathrm{C}$ que ha experimentado la atmósfera desde la revolución industrial $(\underline{119}, \underline{120})$.

\section{RADIACIÓN UVY LA INTERACCIÓN CON FACTORES BIÓTICOS}

En 1994, Caldwell y Flint especularon que el efecto más importante de un aumento de la radiación UV debiera manifestarse a nivel de ecosistemas, donde pequeños cambios en plantas individuales expuestas a UV-B se amplificarían con implicancia directa sobre múltiples niveles tróficos (118).

En el campo, el principal efecto del aumento de la radiación ultravioleta parece ser respuestas fotomorfogénicas que inducen una alteración en la partición y localización del carbono más que en reducciones significativas del crecimiento o de la acumulación de biomasa (그).

Independientemente de la sensibilidad o tolerancia que presenten las plantas frente al efecto de la radiación UV-B, las alteraciones que se producen en la composición química de éstas afectan significativamente la interacción que existe entre las plantas y las distintas comunidades de microorganismos. Es así como muchos de los cambios observados en la población de herbívoros, hongos y bacterias con relación a la exclusión y/o el aumento de la radiación UV-B, han sido correlacionados con los cambios que se generan en los metabolitos secundarios de plantas superiores $(\underline{121}, \underline{122})$, los que estarían mediando múltiples respuestas tróficas por efecto 
UV-B. Estos compuestos considerados filtros de radiación UV-B en las plantas actuarían también como compuestos antiherbívoros haciéndolas más resistentes al ataque de patógenos, mientras que otros metabolitos secundarios que son secuestrados por herbívoros específicos desde sus hospedantes pueden actuar directamente como compuestos de defensa contra sus depredadores o como precursores de compuestos de defensa (121). De esta manera, los metabolitos secundarios serían los principales candidatos implicados en mediar múltiples respuestas tróficas provocando consecuencias para autótrofos y para subsecuentes niveles tróficos $(\underline{121}, \underline{123})$.

Así también, muchos microorganismos que viven en la superficie de la hoja están expuestos al efecto de la radiación ultravioleta en parte o todo su ciclo de vida. Para estos microorganismos, la radiación UV impone una intensa selección, ya que a menudo son vulnerables al efecto UV durante los procesos de esporulación, dispersión e infección. El daño en el DNA es uno de los principales efectos observados en algunos hongos y bacterias expuestas a UV, incluyendo patógenos y microorganismos implicados en el proceso de descomposición de la materia orgánica en el suelo (121). Los daños que provoca la radiación UV-B en el DNA de estos microorganismos genera -vía mutagénesis- cambios en su composición genotípica, los que son heredables, aumentando de esta manera la variación genética en este nivel trófico $(\underline{121}, \underline{123})$. Estudios en campo del efecto de la UV en sistemas naturales muestran una reducción sostenida de herbívoros conforme aumenta la radiación UV-B y, por el contrario, la reducción de la radiación UV-B mediante filtros tiende a aumentar la severidad de las enfermedades (123). En este sentido, es importante hacer la distinción entre el efecto directo de la radiación UV-B que afecta la tasa de crecimiento de microorganismos y el efecto indirecto de la luz ultravioleta que altera la composición química de la planta hospedante, haciéndola más resistente al ataque de distintos patógenos $(\underline{123}, \underline{124})$.

Estudios en campo están empezando a mostrar que cambios en la radiación UV-B pueden tener a futuro consecuencias para los procesos del suelo $\mathrm{y}$, de organismos asociados, aun no estando directamente expuestos a radiación UV incidente (119, 125). Por ejemplo, microorganismos importantes en la nutrición mineral como micorrizas y hongos que están asociados a raíces disminuyen sustancialmente con el aumento de la radiación UV-B $(\underline{125})$, mientras que las interacciones entre plantas y bacterias simbióticas fijadoras de nitrógeno podrían ser estimuladas por radiación UV-B. Pinto y colaboradores (2002) observaron que el proceso de nodulación en plantas de poroto era estimulado por la radiación UV-B en conjunto con la producción de compuestos absorbedores de UV en raíces (126).

Aunque la radiación UV-B no llega a penetrar significativamente en el suelo, tiene un efecto directo en la descomposición de las hojas, al estimular el rompimiento fotoquímico de lignina y/o alterar la comunidad de microorganismos que participan en el proceso de descomposición de la materia orgánica, lo que genera importantes consecuencias para el ciclo de nutrientes minerales en el suelo (127).

La interacción y el balance total de todos estos procesos no han sido muy estudiados, sin embargo, la evidencia existente indica que el efecto directo de la UV-B en la descomposición de la materia orgánica varía entre especies, está confinada a los primeros meses después de la caída de las hojas y son relativamente pequeños en magnitud (118). Los mecanismos involucrados en el proceso de descomposición parecen estar relacionados a cambios persistentes en la calidad de la materia seca que proviene de la exposición a UV-B durante el crecimiento de la hoja, es decir, se relacionan con el contenido de flavonoides y otros compuestos fenólicos, así como la proporción de lignina y celulosa en los tejidos vegetales, lo que puede afectar o alterar la tasa de descomposición con implicancia directa en los ciclos biogeoquímicos $(\underline{126}, \underline{128})$.

\section{RADIACIÓN UV Y LA INTERACCIÓN CON OTROS FACTORES DEL CAMBIO CLIMÁTICO}

El efecto combinado de una alta radiación UV-B y déficit hídrico ha sido abordado en diversos estudios, en los que se deja de manifiesto una reducción del crecimiento de las plantas y la alteración de distintos parámetros fisiológicos y bioquímicos (129). Ambos factores ambientales actuarían sinérgicamente sobre el metabolismo secundario de las plantas aumentando la producción de flavonoides (130). Además, la sequía y los altos flujos de radiación UV-B inducirían la producción de ceras cuticulares favoreciendo de esta manera la reflexión de la luz y la conservación del agua (24).

Un elevado $\mathrm{CO}_{2}$ por sí solo tiene un efecto benéfico en algunas variedades de soya (131), debido a cambios morfológicos asociados a altos niveles de $\mathrm{CO}_{2}$ que favorecen la fijación fotosintética del 
carbono, aumentando la productividad de la soya entre un 24 a $37 \%$ (132). El aumento de la producción de biomasa y del rendimiento de las semillas de soya observado a elevado $\mathrm{CO}_{2}$, se mantiene cuando este factor ambiental interactúa con UV-B, debido a que el aumento de $\mathrm{CO}_{2}$ compensa parcialmente el efecto negativo que genera la radiación UV-B en el crecimiento vegetativo y en procesos fisiológicos (132). Por el contrario, en plantas de tomate y de algodón, la combinación de alta radiación UV-B y elevado $\mathrm{CO}_{2}$ no disminuye el efecto adverso de la UV-B, incluso provoca un daño más severo que en condiciones de $\mathrm{CO}_{2}$ ambiental $(\underline{133}, \underline{134})$.

Por otra parte, Mark y Tevini ,en 1996, observaron que la reducción del crecimiento provocada por alta radiación UV-B en Helianthus annuus L., cv. Polstar y en Zea mays L., cv. Zenit 2000, podía ser revertida con el aumento de la temperatura en $4^{\circ} \mathrm{C}(\underline{10})$. Esta interacción benéfica entre alta radiación UV-B y altas temperaturas, ha sido atribuida a una mayor tasa fotosintética que tendrían las plantas debido a que tanto la UV-B como las altas temperaturas facilitarían la activación de distintos mecanismos de protección, como por ejemplo aumento de la producción de flavonoides y de la síntesis de proteínas de shock término conocidas como HSP (heat shock protein) $(\underline{10}, \underline{119})$. Además, la interacción radiación UV-B y temperatura serían moduladores positivos de la actividad de la enzima nitrato reductasa (135). No obstante, en soya cultivada con altos flujos de radiación UV-B, el aumento de $1^{\circ} \mathrm{C}$ en la temperatura genera alteraciones en la morfología del polen y en la germinación (131), lo que tiene un impacto negativo en la productividad de este cultivo, la que es reducida en un $17 \%(\underline{131}, \underline{136})$. Pero, durante el crecimiento vegetativo de esta especie, el aumento de $\mathrm{CO}_{2}$ compensa el efecto dañino que producen las altas temperaturas y altos flujos de radiación UV-B sobre distintos aspectos fisiológicos (137).

\section{CONCLUSIONES}

Los distintos mecanismos de adaptación a radiación UV-B que se han documentado en plantas, hasta la fecha se relacionan esencialmente con estrategias que desarrollan éstas para evitar la penetración de este tipo de luz. Los cambios morfológicos que involucran la reducción del crecimiento son, sin lugar a duda, la respuesta más observada y se entiende como un mecanismo de protección que persigue disminuir la cantidad de tejido expuesto y en consecuencia disminuir la absorción de luz UV. Es común observar también cambios en el contenido de ceras que favorecen la reflexión de la luz y aumento en el contenido de compuestos absorbedores de radiación UV como fenoles y flavonoides, todos los cuales actuarían como filtros para impedir la penetración de esta radiación y prevenir el efecto dañino de la luz UV-B sobre distintos componentes celulares. Además, los metabolitos secundarios serían un factor común que mediaría en condiciones de radiación UV-B respuestas con consecuencias tanto para autótrofos como para subsecuentes niveles tróficos, lo que puede afectar las interacciones competitivas, el ciclo de nutrición, el ciclo y secuestro de carbono, y otros procesos a nivel de ecosistema.

Las investigaciones analizadas en este trabajo muestran además que las plantas expuestas a radiación UV-B activan mecanismos de protección contra el daño oxidativo sobre lípidos y proteínas. La inducción de la transcripción de genes relacionados con la fotosíntesis, estrés oxidativo y con el metabolismo de los fenilpropanoides demuestran el amplio reajuste de la transcripción genómica que demanda a las plantas mantener la homeostasis fisiológica en condiciones de estrés por UV. Además, demuestran la implicancia de ROS y RNS como promotores de genes que actúan en etapas tempranas del metabolismo de los fenilpropanoides, compuestos que tienen un rol como fotoprotectores y como responsables de la modulación de la respuesta de las plantas a radiación ultravioleta-B.

Por otra parte, la mantención de la estabilidad genómica llevada a cabo predominantemente por las enzimas ADN-fotoliasa resulta de vital importancia para la sobrevivencia de las plantas en condiciones de alta radiación UV-B. Esto debido a que esta radiación afecta directamente la integridad de las moléculas de ADN. Las plantas cuentan también con el mecanismo de reparación de ADN por excisión al igual que los organismos animales; no obstante, la fotorreparación cobra vital relevancia al ser un proceso clave en la protección de células no proliferativas de plantas que están continuamente sometidas al efecto UV-B de la radiación solar.

Si bien las plantas han desarrollado desde temprano en la evolución mecanismos de protección lo suficientemente eficientes para prevenir el efecto dañino de la radiación UV natural, las predicciones de un aumento de la radiación UV-B solar podrían tener un gran impacto en la productibilidad de los 
cultivos, debido principalmente a la disminución del crecimiento que se observa en las distintas especies vegetales estudiadas y al efecto que tiene sobre hongos y bacterias que son generalmente más sensibles a la UV-B que las plantas. Por lo tanto, se hace necesario abordar esta problemática de manera global, con más estudios que pudiesen predecir los cambios que provocaría el aumento de la radiación UV-B en la distribución de la vegetación y en la biocenosis asociada.

Además, en el contexto del cambio climático experimentado en los últimos años, donde no sólo se ha producido un aumento de la radiación UV-B sino también aumento de la concentración atmosférica de $\mathrm{CO}_{2}$ y de la temperatura, es difícil poder

\section{LITERATURA CITADA}

1. BLUMTHALER, M.; AMBACH, W. 1990. Indication of increasing solar ultraviolet-B radiation flux in alpine regions. Science; 248 (4952): 206-208.

2. DENTENER, F.; DERWENT, R.; DLUGOKENCKY, E.; HOLLAND, E.; ISAKSEN, I.; KATIMA, J.; KIRCHHOFF, V.; MATSON, P.; MIDGLEY, P.; WAND, M. 2001. Atmospheric chemistry and greenhouse gases. In Houghton, J.T.; Ding, J.; Griggs, D.J.; Noguer, M.; Van der Linden, PJ; Dai, X; Maskell, K.; Jonson, C.A.; (Eds.) Climate Change 2001: The Scientific Basis. Contributions of Working Group I to the Third Assessment Report of the Intergovernmental Panel on Climate Change. Cambridge University Press, New York, 881 pp.

3. UNEP. 2002. Executive Summary. Final of UNEP/WMO Scientific Assessment of Ozone Depletion: Prepared by the Scientific Assessment Panel of the Montreal Protocol on Substances that Deplete the Ozone Layer. UNEP, Nairobi.

4. KAKANI, V.G.; REDDY, K.R.; ZHAO, D.; SAILAJA, K. 2003. Field crop responses to ultravioletB radiation: a review. Agr Forest Meteorol 120 (1-4): 191-218.

5. CALDWELL, M.M.; ROBBERECHT, R.; FLINT, S.D. 1983. Internal filters: Prospects for UV-acclimation in higher plants. Physiol Plant 58 (3): 445-450.

6. HE,J.; HUANG,L.K.; CHOW,W.S.; WHITECROSS, M.I.; ANDERSON, J.M. 1993. Effects of supplementary ultraviolet-B radiation on rice and pea plants. Aust J Plant Physiol 20 (2), 129-142.

7. TEVINI, M; TERAMURA, A.H. 1989. UV-B effects on terrestrial plants. Photochem Photobiol 50 (4): 479-487.

8. SEARLES, P.S.; CALDWELL, M.M.; WINTER, K. 1995. The response of five tropical dicotyledon species to solar ultraviolet-B radiation. Am J Bot 82: 445-453.

9. LI, Y.; YUE, M.; WANG, X.L. 1998. Effects of enhanced ultraviolet-B radiation on crop structure, growth and yield components of spring wheat under field conditions. Field Crops Research 57 (3): 253-263. predecir cómo afectará las complejas interacciones que suceden entre procesos ecológicos y climáticos. Por tal motivo, es importante contar con más información que haga posible predecir las consecuencias que podrían tener las interacciones de estos factores, por ejemplo, en la eficiencia de los mecanismos enzimáticos de fotoprotección, en la asimilación de $\mathrm{CO}_{2} \mathrm{y}$ futura disponibilidad de carbono.

\section{AGRADECIMIENTOS}

A las instituciones que financiaron la beca de Doctorado de Libertad Carrasco-Ríos: Gobierno Regional de Tarapacá, CONYCYT y CIHDE.

10. MARK, U.; TEVINI, M. 1996. Combination effects of UV-B radiation and temperature on sunflower (Helianthus annus L., cv Polstar) and maize (Zea mays L., cv. Zenit 2000) seedlings. J Plant Physiol 148 (1-2): 49-56.

11. GONZALEZ, R.; PAUL, N.D.; PERCY, K.; AMBROSE, M.; MCLAUGHLIN, C.K.; BARNES, J.D.; ARESES, M.; WELLBURN, A.R. 1996. Responses to ultraviolet-B radiation (280-315nm) of pea (Pisum sativum) lines differing in leaf surface wax. Physiol Plant 98 (4): 852-860.

12. TERAMURA, A.H.; TEVINI, M.; IWANZIK, W. 1982. Effects of ultraviolet-B irradiation on plants during mild water stress. 1. Effects on diurnal stomatal resistance. Physiol Plant 57 (2): 175-180.

13. MURALI, NS; TERAMURA, A.H. 1986. Effectiveness of UV-B radiation on the growth and physiology of fieldgrown soybean modified by water stress. Photochem Photobiol 44 (2): 215-219.

14. NOGUÉS, S.; ALLEN, D.J.; MORISON, JIL; BAKER, N.R. 1998. Ultraviolet-B radiation effects on water relations, leaf development, and photosynthesis in droughted pea plants. Plant Physiol 117 (1): 173-181.

15. MACADAM, J.W.; VOLENEC, J.J.; NELSON, C.J. 1989. Effects of nitrogen on mesophyll cell division and epidermal cell elongation in tall fescue leaf blades. Plant Physiol 89 (2): 549-556.

16. DALE, J.E. 1988. The control of leaf expansion. Annu Rev Plant Physiol Plant Mol Biol 39: 267-295.

17. LIU, L.; GITZ III, D.C.; MCCLURE, J.W. 1995. Effects of UV-B on flavonoids, ferulic acid, growth, and photosynthesis in barley primary leaves. Physiol Plant 93 (4): 725-733.

18. MEPSTED, R.; PAUL, N.D.; STEPHEN, J.; CORLETT, J.E.; NOGUÉS, S.; BAKER, N.R.; JONES, H.G.; AYRES, P.G. 1996. Effects of enhanced UV-B radiation on pea (Pisum sativum L.) grown under field conditions in the UK. Glob Change Biol 2 (4): 325-334.

19. ALLEN, D.J.; NOGUÉS, S.; BAKER, N.R. 1998. Review article. Ozone depletion and increased UV-B radiation: is 
there a real threat to photosynthesis? J Exp Bot 49 (328): 1775-1788.

20. BALLARÉ, CL; BARNES, PW; FLINT, SD; PRICE, S. 1995. Inhibition of hypocotyl elongation by ultraviolet-B radiation de-etiolating tomato seedlings. II. Time-course comparison with flavonoid responses and adaptive significance. Physiol Plant 93 (4): 593-601.

21. LOGEMANN, E.; WU, S.C.; SCHRÖDER, J.; SCHMELZER, E.; SOMSSICH, I.E.; HAHLBROCK, K. 1995. Gene activation by UV light, fungal elicitor or fungal infection in Petroselinum crispum is correlated with repression of cell cycle-related genes. Plant J 8 (6): 865-876.

22. STAXÉN, I.; BERGOUNIOUX, C.; BORNMAN, J.F. 1993. Effect of ultraviolet radiation on cell division and microtubule organization in Petunia hybrida protoplasts. Protoplasma 173 (1-2): 70-76.

23. CASATI, P.; ZHANG, X.; BURLINGAME, A.L.; WALBOT, V. 2005. Analysis of leaf proteome after UV-B irradiation in maize lines differing in sensitivity. Molecular \& Cellular Proteomics 4 (11): 1673-1679.

24. STEINMÜLLER, D.; TEVINI, M. 1985. Action of ultraviolet radiation (UV-B) upon cuticular waxes in some crop plants. Planta 164 (4): 557-564.

25. ROBBERECHT, R.; CALDWELL, M.M. 1980. Leaf ultraviolet optical properties along a latitudinal gradient in the Arctic-alpine life zone. Ecology 61: 612-619.

26. DAI, Q.; CORONEL, V.P.; VERGARA, B.S.; BARNES, P.W.; QUINTOS, A.T. 1992. Ultraviolet-B radiation effects on growth and physiology of four rice cultivars. Crop Sci 32: 1269-1274.

27. LÁPOSI, R.; VERAS, S.; LAKATOS, G.; OLÁH, V.; FIELDSEND, A.; MÉSZÁROS, I. 2009. Responses of leaf traits of European beech (Fagus sylvatica L.) saplings to supplemental UV-B radiation and UV-B exclusion. Agricultural and Forest Meteorology 149: 745-755.

28. CASSI-LIT, M; WHITECROSS, M.I. NAYUDU M, TANNER GJ. 1997. UV-B irradiation induces differential leaf damage, ultrastructural changes and accumulation of species phenolic compounds in rice cultivares. Aust J Plant Physiol 24 (3): 261-274.

29. FAGERBERG, W.R.; BORNMAN, J.F. 1997. Ultraviolet-B radiation causes shade-type ultrastructural changes in Brassica napus. Physiol Plant 101 (4): 833-844.

30. SANTOS, A.; ALMEIDA, J.M.; SANTOS, I.; SALEMA, R. 1998. Biochemical and ultrastructural changes in pollen of Zea mays L. grown under enhanced UV-B radiation. Ann of Bot 82: 641-645.

31. BARNES, P.W.; BALLARE, C.L.; CALDWELL, M.M. 1996. Photomorphogenic effects of UV-B radiation on plants: consequences for light competition. J Plant Physiol 148 (1-2), 15-20.

32. LINGAKUMAR, K.; KULANDAIVELU, G. 1993. Changes induced by ultraviolet-B radiation in vegetative growth, foliar characteristic and photosynthetic activities in Vigna ungiculata. Aust J Plant Physiol 20 (3): 299-308.

33. GILLER, IUE; SHCHERBAKOVA, IIU.; LIPKINA, B.I.; KARIEVA, F.A.; SHISHKIN, V.A. 1991. The effect of medium-wave UV-radiation on the photosynthetic apparatus and the productivity of higher plants. Kosm Bio Aviakosm Med 25 (4): 26-29.
34. KRAUSE, GH; SCHMUDE, C.; GARDEN, H.; KOROLEVA, OY; WINTER, K. 1999. Effects of solar ultraviolet radiaction on the potential efficiency of photosystem II in leaves of tropical plants. Plant Physiol 121 (4): 1349-1358.

35. VASS, I.; STYRING, S.; HUNDAL, T.; KOIVUNIEMI,A.; ARO, E.M.; ANDERSSON, B. 1992 Reversible and irreversible intermediate during photoinhibition of ohtosystem II: stable reduced QA species promote chlorophyll triplet formation. Proc Natl Acad Sci, USA 89 (4): 1408-1412.

36. BERGO, E.; SEGALLA, A.; GIACOMETTI, G.M.; TARANTINO, D.; SOAVE, C.; ANDREUCCI, F.; BARBATO, R. 2003. Role of visible light in the recovery of photosystem II structure and function from ultraviolet-B stress in higher plants. J Exp Bot 54 (388): 1665-1673.

37. BORNMAN, J.F. 1989. New trends in photobiology: Target sites of UV-B radiation in photosynthesis of higher plants. Photochem Photobiol 4 (2): 145-158.

38. HORTON, P.; RUBAN, A. 2005. Molecular design of the photosystem II light-harvesting antenna: photosynthesis and photoprotection. J Exp Bot 56 (411): 365-373.

39. BARBATO, R.; BERGO, E.; SZABÒ, DALLA VECCHIA, F.; GIACOMETTI, G.M. 2000. Ultraviolet B exposure of whole leaves of barley affects structure and functional organization of photosystem II. J Biol Chem 275 (15): 10976-10982.

40. HAKALA, M.; RANTAMÄKI, S.; PUPUTTI, E.-M.; TYYSTJÄRVI, T.; TYYSTJÄRVI, E. 2006. Photoinhibition of manganese enzymes: insights into the mechanism of photosystem II photoinhibition. J Exp Bot 57 (8): 1809-1816.

41. HIDEMA, J.; KUMAGAI, T. 2006. Sensitivity of rice to ultraviolet-B radiation. Ann Bot 97 (6): 933-942.

42. VASS, I.; SASS, L.; SPETEA, C.; BAKOU, A.; GHANOTAKIS, D.F.; PETROULEAS, V. 1996. UV-B induced inhibition of photosystem II electron transport studied by EPR and chlorophyll fluorescence. Impairment of donor and acceptor side components. Biochemistry 35 (27): 8964-8973.

43. BARBATO, R.; FRIZZO, A.; FRISO, G.; RIGONI, F.; GIACOMETTI, G.M. 1995. Degradation of the D1 protein of photosystem II reaction centre by ultraviolet $\mathrm{B}$ radiation requires the presence of functional manganese on the donor side. Eur J Biochem 227 (3): 723-729.

44. BOOIJ-JAMES I.S., DUBE S.K., JANSEN MAK EDELMAN, M., MATTOO AK. 2000. Ultraviolet-B radiation impacts light-mediated turnover of the photosystem II reaction center heterodimer in Arabidopsis mutants altered in phenolic metabolism. Plant Physiol 124 (3): 1275-1283.

45. BAENA-GONZÁLEZ, E.; ARO, E.M.; 2002. Biogenesis, assembly and turnover of photosystem II units. Philos Trasns R Soc Lond B Biol Sci 357 (1426): 1 451-1460.

46. ZHANG L,ARO E.M. 2002. Synthesis, membrane insertion and assembly of the chloroplast-encoded D1 protein into photosystem II. FEBS Lett 551 (1): 13-18.

47. FRISO, G.; SPETEA, C.; GICOMETTI, G.M.; VASS, I.; BARBATO, R. 1994. Degradation of photosystem II reaction center D1-protein induced by UVB radiation in isolated thylakoids. Identification and characterization of C- and N-terminal breakdown products. Biochem Biophys 1184 (1): 78-84. 
48. JANSEN, MAK; GREEENBERG, B.M.; EDELMAN, M.; MATTOO, A.-K.; GABA, V. 1996. Accelerated degradation of the D2 protein of photosystem II under ultraviolet radiation. Photochem Photobiol 63 (6): 814-817.

49. ARO, E.-M.; VIRGIN, I.; ANDERSON, B. 1993. Photoinhibition of photosystem II. Inactivation, protein damage and turnover. Biochim Biophys Acta 1143 (2): 113-134.

50. BORNMAN, J.F.; VOGELMANN, T.C. 1991. Effects of UV-B radiation on leaf optical properties measured with fibre optics. J Exp Bot 42 (4): 547-554.

51. MIRECKI, R.M.; TERAMURA, A.H. 1984. Effects of ultraviolet-B irradiance on soybean. The dependence of plant sensitive on the photosynthetic photon flux density during and after leaf expansion. Plant Physiol 74: 475-480.

52. TEVINI, M.; BRAUN J.; FIESER, G. 1991. The protective function of the epidermal layer of rye seedlings against ultraviolet-B radiation. Photochem Photobiol 53 (3): 329-333.

53. TERAMURA, A.H.; SULLIVAN, J.H. 1994. Effects of UV-B radiation on photosynthesis and growth of terrestrial plants. Photosynthesis Res 39 (3): 463-473.

54. OLSSON, L.C.; FRAYSSE, L.; BORNMAN, J.F. 2000. Influence of high light and UV-B radiation on photosynthesis and D1 turnover in atrazine-tolerant and -sensitive cultivars of Brassica napus. J Exp Bot 51 (343): 265-274.

55. BAENA-GONZÁlEZ, E.; BARBATO, R.; ARO, E.-M. 1999. Role of phoshorylation in the repair cycle and oligomeric structure of photosystem II. Planta 208 (2): 196-204.

56. FOYER, C.H.; LELANDAIS, M.; KUNERT, K.J. 1994. Photooxidative stress in plants. Physiol Plant 92 (4): 696-717.

57. BARBER, J.; ANDERSSON, B. 1992. Too much of a good thing: light can be bad for photosynthesis. Trends in Biochemical Sciences 17: 61-66.

58. SURABHI, G.K.; REDDY, K.R.; SINGH, S.K. 2009 Photosynthesis, fluorescence, shoot biomass and seed weight responses of three cowpea (Vigna unguiculata (L.) walp.) cultivars with contrasting sensitivity to UV-B radiation. Environ Exp Bot: en prensa.

59. BROSCHÉ M., SCHULER M.A. KALBINA I., CONNOR, L., STRID A. 2002. Gene regulation by low level UV-B radiation: identification by DNA arrays analysis. Photochem Photobiol Sci. 1: 656-664.

60. CASATI, P.; WALBOT, V. 2003. Gene expression profiling in response to ultraviolet radiation in maize genotypes with varying flavonoid content. Plant Physiol 132 (4): 1739-1754.

61. JORDAN, B.R.; HE, J.; CHOW, S.; ANDERSON, J.M. 1992. Changes in mRNA levels and polypeptide subunits of ribulose 1,5-biphosphate carboxilase in response to supplementary ultraviolet-B radiation. Plant Cell Environ 15: 91-98

62. VON CAEMMERER S., FARQUHAR G.D. 1981. Some relationships between the biochemistry of photosynthesis and the gas exchange of leaves. Planta 153: 376-387.

63. ALLEN, D.J.; MCKEE, I.F.; FARAGE, P.K.; BAKER, N.R. 1997. Analysis of limitations to CO2 assimilation on exposure of leaves of two Brassica napus cultivars to UV-B. Plant Cell Environ 20: 633-640.
64. VU,CV; ALLEN, JR, L.H.; GARRARD, L.A. 1982. Effects of supplemental UV-B radiation on primary photosynthetic carboxylating enzymes and soluble proteins in leaves of C3 and C4 crop plants. Physiol Plant 55: 11-16.

65. STRID, A.; CHOW, W.S.; ANDERSON, J.M. 1990. Effects of supplementary ultraviolet-B radiation on photosynthesis in Pisum sativum. Biochimica et Biophysica Acta 1020: 260-268.

66. BROSCHÉ, M.; FANT, C.; BERGKVIST, S.W.; STRID, H.; SVENSK, A.; OLSSON, O.; STRID, A. 1999. Molecular markers for UV-B stress in plants: alteration of the expression of four classes of genes in Pisum sativum and the formation of high molecular mass RNA adducts. Biochim Biophys Acta 1447 (2-3): 185-198.

67. LI, J.; OU-LEE, T.M.; RABA, R.; AMUNDSON, R.G. 1993. Last RL. Arabidopsis flavonoid mutants are hypersensitive to UV-B irradiation. Plant Cell 5 (2): 171-179.

68. LANDRY, L.G.; CHAPPLE, C.C.S.; LAST, R.L. 1995. Arabidopsis mutants lacking phenolic sunscreens exhibit enhanced ultraviolet-B injury and oxidative damage. Plant Physiol 109 (4): 1159-1166.

69. ROZEMA, J.; BJÖRN, L.O.; BORNMAN, J.F.; GABERSCIK, A.; HÄDER, D.P.; TROST, T.; GERM, M.; KLISCH, M.; GRÖNIGER, A.; SINHA, R.P.; LEBERT, M.; HE, Y.Y.; BUFFONI-HALL, R.; DE BAKKER, N.V.J.; VAN DE STAAIJ, J.; MEIJKAMP, B.B. 2002. The role of UV-B radiation in aquatic and terrestrial ecosystems-an experimental and functional analysis of the evolution of UV-absorbing compounds. J Photochem Photobiol 66 (1): 2-12.

70. JOHNSON, CB; KIRBY, J.; NAXAKIS, G.; PEARSON, S. 1999. Substantial UV-B-mediated induction of essential oils in sweet basil (Ocimum basilicum L.). Phytochemistry 51 (4): 507-510.

71. ZAVALA J.A., RAVETTA D.A. 2002. The effect of solar UV-B radiation on terpenes and biomass production in Grindelia chiloensis (Asteraceae), a woody perennial of Patagonia, Argentina. Plant Ecology 161: 185-191.

72. BATTAGLIA P.R., BRENNAN T.M. 2000. Differential effects of short-term exposure to ultraviolet-B radiation upon photosynthesis in cotyledons of a resistant and a susceptible species. Int J Plant Sci 161 (5): 771-778.

73. BASSMAN, J.H. 2004. Ecosystem consequences of enhanced solar ultraviolet radiation: secondary plant metabolites as mediators of multiple trophic interactions in terrestrial plant communities. Photochem Photobiol 79 (5): 382-398.

74. VU, C.V.; ALLEN, JR. L.H.; GARRARD, L.A. 1981. Effects of supplemental UV-B radiation on growth and leaf photosynthetic reactions of soybean (Glycine max). Physiol Plant 52 (3): 353-362.

75. CEN, Y.P.; BORNMAN, J.F. 1990. The response of bean plants to UV-B radiation under different irradiances of background visible light. J Exp Bot 41 (11): 1489-1495.

76. OUWERKERK，P.B.F.; HALLARD，D.; VERPOORTE, R.; MEMELINK, J. 1999. Identification of UV-B Light-responsive regions in the promoter of the tryptophan decarboxylase gene from Catharanthus roseus. Plant Mol Biol 41 (4): 491-503.

77. LYDON, J.; TERAMURA, A.H.; COFFMAN, C.B. 1987. UV-B radiation effects on photosynthesis, growth 
and cannabinoid production of two Cannabis sativa chemotypes. Photochem Photobiol46 (2): 201-206.

78. LINDROTH, R.L.; HOFMANN, R.W.; CAMPBELL, B.D.; MCNABB, W.C.; HUNT, D.Y. 2000. Population differences in Trifolium repens $\mathrm{L}$. response to ultraviolet-b radiation: foliar chemistry and consequences for two lepidopteran herbivores. Oecologia 122 (1): 20-28.

79. BARABÁS K,N, SZEGLETES Z, PESTENÁCZ A, FÜLÖP K, ERDEI, L. 1998. Effects of excess UV-B irradiation on the antioxidant defence mechanisms in wheat (Triticum aestivum L.) seedlings. J Plant Physiol 153: 146-153.

80. PINTO, M.E.; CASATI, P.; HSU, T.P.; KU, M.S.B.; EDWARDS, G.E. 1999. Effects of UV-B radiation on growth, photosynthesis, UV-B absorbing compounds and NADP-malic enzyme in bean (Phaseolus vulgaris L.) grown under different nitrogen conditions. Photochem Photobiol 48: 200-209.

81. HOFMANN, R.W.; SWINNY, E.E.; BLOOR, SJ; MARKHAM, K.R.; RYAN, K.G.; CAMPBELL, B.D.; JORDAN, B.R.; FOUNTAIN, D.W. 2000. Responses of nine Trifolium repens $\mathrm{L}$. populations to ultraviolet-B radiation: differential flavonol glycoside accumulation and biomass production. Ann Bot 86 (3): 527-537.

82. BIEZA, K; LOIS, R. 2001. An Arabidopsis mutant tolerant to lethal ultraviolet-B levels shows constitutively elevated accumulation of flavonoids and other phenolics. Plant Physiol 126 (3): 1105-1115.

83. RAO, M.V.; ORMROD, D.P. 1995. Ozone exposure decreases UVB sensitivity in a UVB-sensitive flavonoid mutant of Arabidopsis. Photochem Photobiol 61(1): 71-78.

84. RYAN, K.G.; SWINNY, E.E.; MARKHAM, K.R.; WINEFIELD, C. 2002. Flavonoid gene expression and UV photoprotection in transgenic and mutant Petunia leaves. Phytochemistry 59 (1): 23-32.

85. RYAN, K.G.; SWINNY, E.E.; WINEFIELD, C.; MARKHAM, K.R. 2001. Flavonoids and UV photoprotection in Arabidopsis mutants. Z Naturforsch 56 (1): 745-754.

86. SELLAPPAN, S.; AKOH, C.C. 2002. Flavonoids and antioxidant capacity of Georgia-grown Vidalia onions. J Agr Food Chem 50 (19): 5338-5342.

87. GOULD, K.S.; MCKELVIE, J.; MARKHAM, K.R. 2002. Do anthocyanins function as antioxidants in leaves? Imaging of $\mathrm{H} 2 \mathrm{O} 2$ in red and green leaves after mechanical injury. Plant Cell Environ 25 (10): 1261-1269.

88. STAPLETON, A.E.; WALBOT, V. 1994. Flavonoids can protect maize DNA from the induction of ultraviolet radiation damage. Plant Physiol 105 (3): 881-889.

89. GREEN, R.; FLUHR, R. 1995. UV-B-induced PR-1 accumulation is mediated by active oxygen species. Plant Cell 7 (2): 203-212.

90. A-H-MACKERNESS, S.A.; JOHN, C.F.; JORDAN, B.; THOMAS, B. 2001. Early signaling in ultraviolet-B reponses: distinct roles for different reactive oxygen species and nitric oxide. FEBS Lett 489: 237-242.

91. IZAGUIRRE, M.M.; SCOPEL, A.L.; BALDWIN, I.T.; BALLARÉ, C.L. 2003. Convergent responses to stress. Solar ultraviolet-B radiation and Manduca sexta herbivory elicit overlapping transcriptional responses in field-grown plants of Nicotiana longiflora. Plant Physiol 132 (4): 1755-1767.

92. WANG, K.; LI, H.; ECKER, J. 2002. Ethylene biosynthesis and signaling networks. The Plant Cell S131-S151.

93. MAZZA, C.A.; BATTISTA, D.; ZIMA, A.M.; SZWARCBERG-BRACCHITTA, M.; GIORDANO, C.V.; ACEVEDO, A.; SCOPEL, A.L.; BALLARÉ, C.L. 1999. The effects of solar UV-B radiation on the growtrh and yield of barley are accompained by increased DNA damage and antioxidant responses. Plant Cell Environ 22: 61-70.

94. RAO, .MV.; PALIYATH, G.; ORMROD, D.P. 1996. Ultraviolet-B and ozone-induced biochemical changes in antioxidant enzymes of Arabidopsis thaliana. Plant Physiol 110 (1): 125-136.

95. STRID, A.; CHOW, W.S.; ANDERSON, J.M. 1994. UV-B damage and protection at the molecular level in plants. Photosynthesis Res 39 (3): 475-489.

96. LI, J.; UCHIDA, T.; TODO, T.; KITAGAWA, T. 2006. Similarities and differences between cyclobutane pyrimidine dimer photolyase and (6-4) photolyase as revealed by resonante raman spectroscopy. J Biol Chem 281 (25): 25551-25559.

97. CASATI, P; WALBOT, V. 2004. Crosslinking of ribosomal proteins to RNA in maize ribosome by UV-B and its effects on translation. Plant Physiol 136 (2): 3319-3332.

98. NAKAJIMA, S.; SUGIYAMA, M.; IWAI, S.; HITOMI, K; OTOSHI, E.; KIM S.T. JIANG, C.Z.; TODO, T.; BRIT, T.A.B.; YAMAMOTO, K. 1998. Cloning and characterization of a gene ( $U V R 3)$ required for photorepair of 6-4 photoproducts in Arabidopsis thaliana. Nucleic Acids Res 26 (2): 638-644.

99. WATERWORTH, W.M.; JIANG, Q.; WEST, C.E.; NIKAIDO, M.; BRAY, C.M. 2002. Characterization of Arabidopsis photolyase enzimes and analysis of their role in protection from ultraviolet-B radiation. J Exp Bot 53 (371): 1005-1015

100. FROHNMEYER, H.; STAIGER, D. 2003. Ultraviolet-B radiation-mediated responses in plants. Balancing damage and protection. Plant Physiol 133 (4): 1420-1428.

101. TUTEJA, N.; AHMAD, P.; PANDA, B.B.; TUTEJA, R. 2009. Genotoxic stress in plants: shedding light on DNA damage, repair and DNA helicases. Mutation Research 681: 134-149.

102. BRITT, A.B.; 1999. Molecular genetics of DNA repair in higher plants. Trends Plant Sci 4: 20-25.

103. KIMURA, S.; TAHIRA, Y.; ISHIBASHI, T.; MORI, Y.; MORI, T.; HASHIMOTO, J; SAKAGUCHI, K. 2004. DNA repair in higher plants; photoreactivation is the major DNA repair pathway in non-proliferating cells while excision repair (nucleotide excision repair and base excision repair) is active in proliferating cells. Nucleic Acids Res 32 (9): 2760-2767.

104. BRITT, A.B.; CHEN, J.J.; WYKOFF, D.; MITCHELL, D.A. 1993. UV-sensitive mutant of Arabidopsis defective in the repair of pyrimidine-pyrimidinone (6-4) dimers. Science 261 (5128): 1571-1574.

105. SUTHERLAND，B.M.; TAKAYANAGI，S.; SULLIVAN, J.H.; SUTHERLAND, J.C. 1996. Plant response to changing environmental stress: cyclobutyl pyrimidine dimer repair in soybean leaves. Photochem Photobiol 64 (3): 464-468. 
106. HIDEMA, J.; KUMAGAI, T.; SOUTHERLAND, B.M. 2000. UV. radiation-sensitive Norin 1 rice contains defective cyclobutane pyrimidine dimer photolyase. Plant Cell 12 (9): 1569-1578.

107. TAYLOR, R.M.; NIKAIDO, O.; JORDAN, B.R.; ROSAMOND, J.; BRAY, C.M.; TOBIN, A.K. 1996. Ultraviolet-B induced DNA lesions and their removal in wheat (Triticum aestivum L.) leaves. Plant Cell Environ 19 (2): 171-181

108. RIQUELME, A.; WELLMANN, E.; PINTO, M. 2007. Effects of ultraviolet-B radiation on common bean (Phaseolus vulgaris $\mathrm{L}$.) plants grown under nitrogen deficiency. Environ Exp Bot 60: 360-367.

109. PINTO, M.; LIZANA, C. 2004. Respuestas y mecanismos de protección en las plantas a la radiación ultravioleta-B: comentarios sobre su evolución. En: Marino H (Ed). Fisiología ecológica en plantas: Mecanismos y respuestas a estrés en los ecosistemas; pp. 43-58.

110. VAN NOORT, J.; ORSINI, F.; EKER, A.; WYMAN, C.; DE GROOTH, B.; GREVE, J. 1999. DNA bending by photolyase in specific and non-specific complexes studied by atomic force microscopy. Nucleic Acids Res; 27()19: 3875-3880.

111. VANDE BERG, B.J.V.; SANCAR, G.B. 1998. Evidence for dinucleotide flipping by DNA-photolyase. J Biol Chem 273 (32): 20276-20284.

112. CARELL, T.; BURGDORF, L.; KUNDU, L.; CICHON,M. 2001. The mechanism of action of DNA photolyases. Current Opinion in Chemical Biology 5 (5): 491-498.

113. KAO, Y.T.; SAXENA, C.; WANG, L.; SANCAR, A.; ZHONG, D. 2005. Direct observation of thymine dimer repair in DNA by photolyase. Proc Natl Acad Sci 102 (45): 16128-16132.

114. LANDRY, L.G.; STAPLETON, A.E.; LIM, J.; HOFFMAN, P.; HAYS, J.B.; WALBOT, V.; LAST, R.L. 1997. An Arabidopsis photolyase mutant is hypersensitive to ultraviolet-B radiation. Proc Natl Acad Sci, USA 94 (1): 328-332.

115. AHMAD,M.;JARILLO,J.; KLIMCZAK,L.; LANDRY,L.; PENG, T.; LAST, R.; CASHMORE, A. 1997. An enzyme similar to animal type II photolyases mediates photoreactivation in Arabidopsis. The Plant Cell 9 (2): 199-207.

116. HEFNER, E.; PREUSS, S.B., BRITT, A.B. 2003. Arabidopsis mutants sensitive to gamma radiation include the homologue of the human repair gene ERCC1. J Exp Bot 54 (383): 669-680.

117. ISHIBASHI, T.; KIMURA, S.; YAMAMOTO, T.; FURUKAWA, T.; TAKATA, K.; UCHIYAMA, Y.; HASHIMOTO, J.; SAKAGUCHI, K. 2003. Rice UVdamaged DNA binding protein homologues are most abundant in proliferating tissues. Gene 308: 79-87.

118. CALDWELL, M.; FLINT, S. 1994. Stratospheric ozone reduction, solar UV-B radiation and terrestrial ecosystems. Clim. Change 28 (4): 375-394.

119. CALDWELL, M.M.; BORNMAN, J.F.; BALLARÉ, C.L.; FLINT, S.D.; KULANDAIVELU, G. 2007. Terrestrial ecosystems, increased solar ultraviolet radiation, and interactions with other climate change factors. Photochem. Photobiol. Sci. 6: 252-266.

120. GIAN-RETO, W.; POST, E.; CONVEY, P.; MENZEL,A.; PARMESAN, C.; BEEBEE, T.J.C.; FROMENTIN, J.M.;
HOEGH-GULDBERG, O.; BAIRLEIN, F. 2002. Ecological responses to recent climate change. Nature 416: 389-394.

121. PAUL, N.; GWYNN-JONES, D. 2003. Ecological roles of solar UV radiation: towards an integrated approach. Trends in Ecology and Evolution 18 (1): 48-55.

122. KUHLMANN, F.; MÜLLER, C. 2009. Developmentdependence effects of UV radiation exposure on broccoli plants and interactions with herbivorus insects. Environmental and Exp Bot 66 (1): 61-68.

123. PAUL N. 2000. Stratospheric ozone depletion, UV-B radiation and crop disease. Environ. Pollut. 108: 343-355.

124. KUNZ, B.A.; CAHILL, D.M.; MOHR, P.G.; OSMOND, M.J.; VONARX, E.J. 2006. Plant responses to UV radiation and links to pathogen resistance. International Rewiev of Cytology 255: 1-40.

125. ZALLER, J.G.; CALDWELL, M.M.; FLINT, S.D.; SCOPEL, A.L.; SALA, O.E.; BALLARÉ, C.L. 2002. Solar UV-B radiation effects below-ground parameters in a fen ecosystem in Tierra del Fuego, Argentina: Implications of stratospheric ozone depletion. Global Change Biol 8: 867-871.

126. PINTO, M.; EDWARDS, G.E.; RIQUELME, A.; KU, M.S.B. 2002. Enhancement of nodulation in bean (Phaseolus vulgaris) by UV-B irradiation. Funct. Plant Biol 29 (10):1189-1196.

127. ZEPP, R.G.; ERICKSON III, D.J.; PAUL, N.D.; SULZBERGER, B. 2001. Interactive effects of solar UV radiation and climate change on biogeochemical cycling. Photochem. Photobiol Sci. 6: 286-300.

128. PANCOTTO ,V.A.; SALA, O.E.; ROBSONS, T.M.; CALDWELL, M.M.; SCOPEL, A.L. 2005. Direct and indirect effects of solar ultraviolet-B radiation on long-term decomposition. Global Change Biology (11): 1982-1989.

129. ALEXIEVA, V.; SERGIEV, I.; MAPELLI, S.; KARANOV, E. 2001. The effect of drought and ultraviolet radiation on growth and stress markers in pea and wheat. Plant Cell Environ 24: 1337-1344.

130. HOFMANN, R.W.; CAMPBELL, B.D.; BLOOR, S.J.; SWINNY, E.E.; MARKHAM, KR; RYAN, K.G.; FOUNTAIN, D.W. 2003. Responses UV-B radiation in Trifolium repens L-physiological links to plant productivity and water availability. Plant Cell Environ 26: 603-612.

131. KOTI, S.; REEDDY, K.R.; REDDY, V.R.; KAKANI, V.G.; ZHAO D. 2005. Interactive effects of cabon dioxide, temperature, and ultraviolet-B radiation on soybean (Glicine max L.) flower and pollen morphology pollen production, germination, and tube lengths. J. Exp. Bot 725-736.

132. AINSWORTH, E.A.; DAVEY, P.A.; BERNACHHI, C.J.; DERMODY, O.C.; HEATON, E.A.; MOORE, DJ; MORGAN, P.B.; NAIDU, S.L.; RA, H.S.Y.; ZHU, X.G.; CURTIS, P.S.; LONG, S.P. 2002. A meta-analysis of elevated $\mathrm{CO} 2$ effects on soybean (Glycine max L.) physiology, growth and yield. Global Change Biol. 8: 695-709.

133. XIUMING, H.; HALE, B.A.; ORMROD, D.P. 1997. The effects of ultraviolet-B radiation and carbon dioxide on growth and photosynthesis of tomato. Can. J. Bot. 75: 213-219.

134. ZHAO, D.; REDDY, K.R.; KAKANI, V.G.; READ, J.; SULLIVAN, J. 2003. Growth and physiological responses of 
cotton (Gossypium hirsutum L.) to elevated carbon dioxide and ultraviolet-B radiation under controlled environment conditions. Plant Cell Environ 26: 771-782.

135. KRYWULT, M; SMYKLA, J; KINNUNEN, H; MARTZ, F; SUTINEN, ML; LAKKALA, K; TURUNEN, M. 2008. Influence of solar UV radiation on the nitrogen metabolism in needles of Scots pine (Pinus sylvestris L.). Environmental Pollution 156 (3): 1105-1111.
136. LOBELL, D.B.; ASNER, G.P. 2003. Climate and management contributions to recent trends in U.S. agricultural yields. Science 299; 1032.

137. KOTI, S.; REDDY, K.R.; KAKANI, V.G.; ZHAO, D.; GAO, W. 2007. Effects of carbon dioxide, temperature and ultraviolet-B radiation and their interactions on soybean (Glicine max L.) growth and development. Environ Exp Bot 60:1-10. 